This item was submitted to Loughborough's Research Repository by the author.

Items in Figshare are protected by copyright, with all rights reserved, unless otherwise indicated.

\title{
Microchannel emulsification
}

PLEASE CITE THE PUBLISHED VERSION

http://www.springerreference.com/

PUBLISHER

(C) Springer

VERSION

AM (Accepted Manuscript)

LICENCE

CC BY-NC-ND 4.0

REPOSITORY RECORD

Vladisavljevic, Goran T., Isao Kobayashi, and Mitsutoshi Nakajima. 2012. "Microchannel Emulsification". figshare. https://hdl.handle.net/2134/10604. 
This item was submitted to Loughborough's Institutional Repository (https://dspace.lboro.ac.uk/) by the author and is made available under the following Creative Commons Licence conditions.

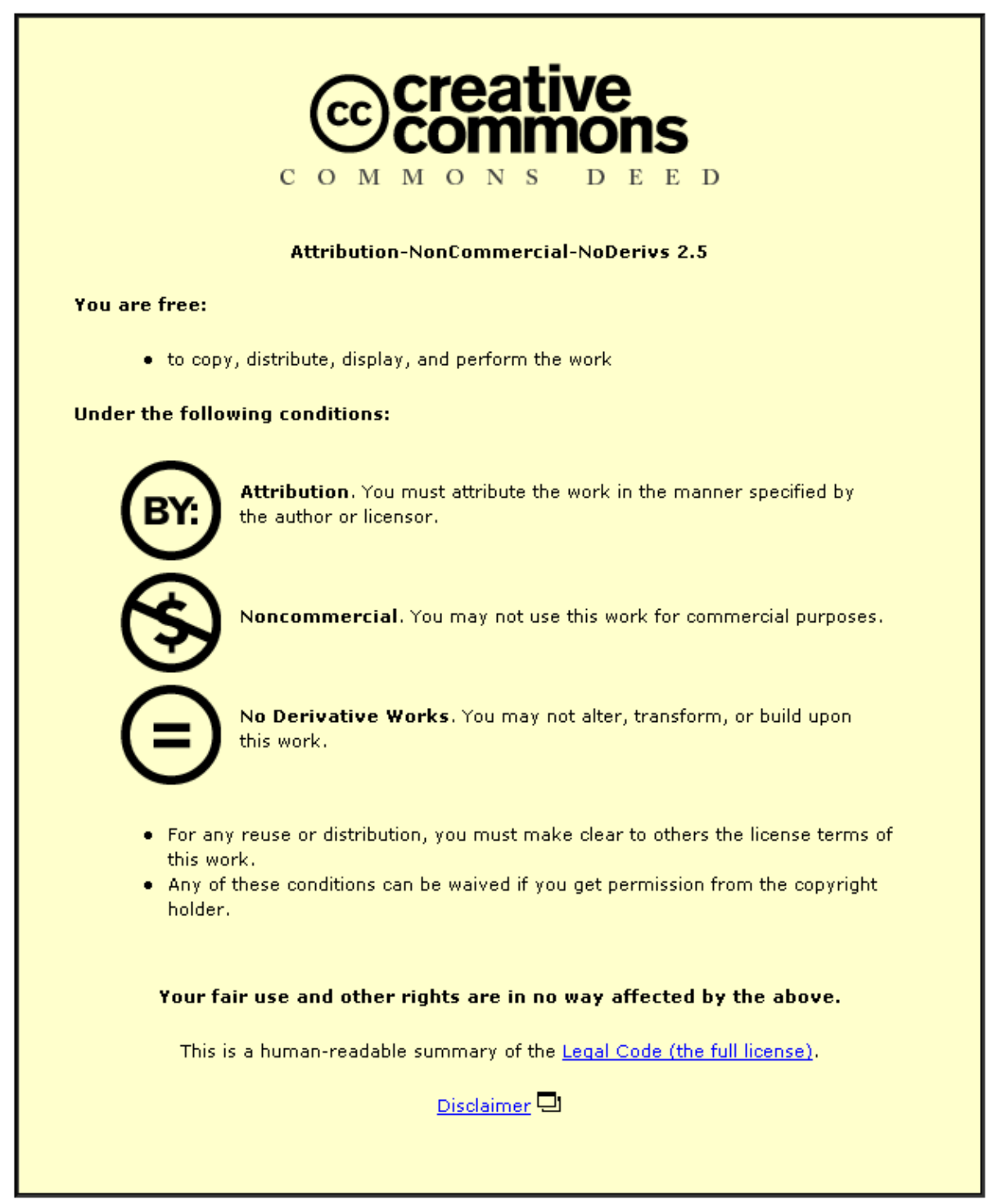

For the full text of this licence, please go to: http://creativecommons.org/licenses/by-nc-nd/2.5/ 


\section{Microchannel emulsification}

Goran T. Vladisavljevića ${ }^{\mathrm{a}}$, Isao Kobayashi ${ }^{\mathrm{b}}$, Mitsutoshi Nakajima ${ }^{\mathrm{b}, \mathrm{c}}$

${ }^{a}$ Chemical Engineering Department, Loughborough University, Loughborough, Leicestershire LE11 3TU, UK.

bational Food Research Institute, National Agriculture and Food Research Organization, 21-12 Kannondai, Tsukuba, Ibaraki 305-8642, Japan.

${ }^{c}$ Faculty of Life and Environmental Sciences, University of Tsukuba, 1-1-1 Tennoudai, Tsukuba, Ibaraki 305-8572, Japan.

Microchannel (MC) emulsification is a process of forming emulsions by injecting a dispersed phase through a multitude of microfabricated MC arrays into the continuous phase. Single crystal silicon MC arrays can be fabricated in the form of horizontal grooves (Kikuchi et al 1992) or vertical straight-through holes (Kobayashi et al 2002).

Grooved-type MC plates are fabricated by photolithography and anisotropic wet etching and can be used in dead-end or cross-flow configuration. In a dead-end module (Fig. 1a), parallel grooves fabricated on a terrace are arranged on all four sides of the plate. The dispersed phase supplied through a central hole is forced to flow through MCs, because the plate is sealed with a transparent cover plate. The dispersed phase takes a disk-like shape on terrace and this shape is characterised by a higher interfacial area per unit volume than a spherical shape, resulting in hydrodynamic instability. This instability is a driving force for spontaneous transformation of dispersed phase into spherical droplets (Sugiura et al. 2002). 
(a) Dead end MC module
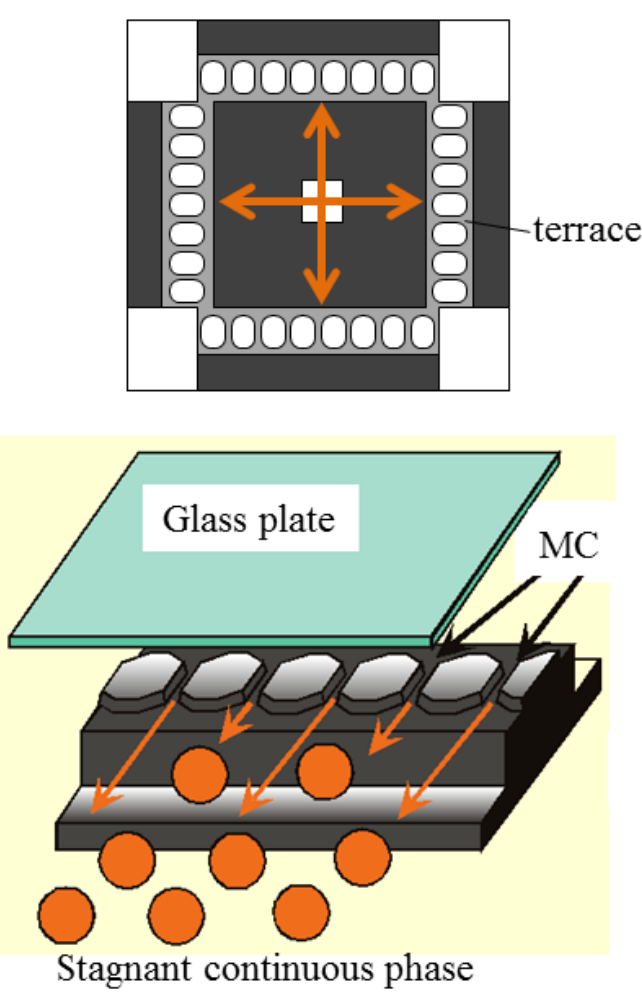

(b) Cross flow MC module

Dispersed phase

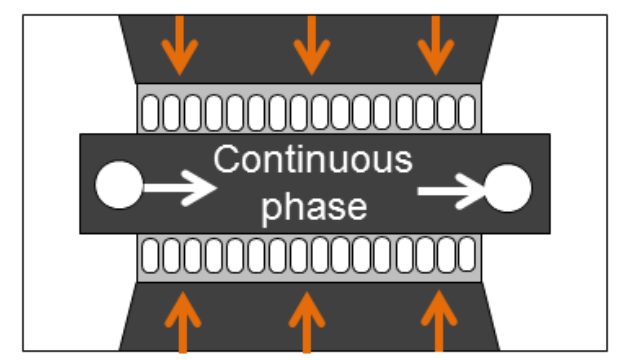

Dispersed phase

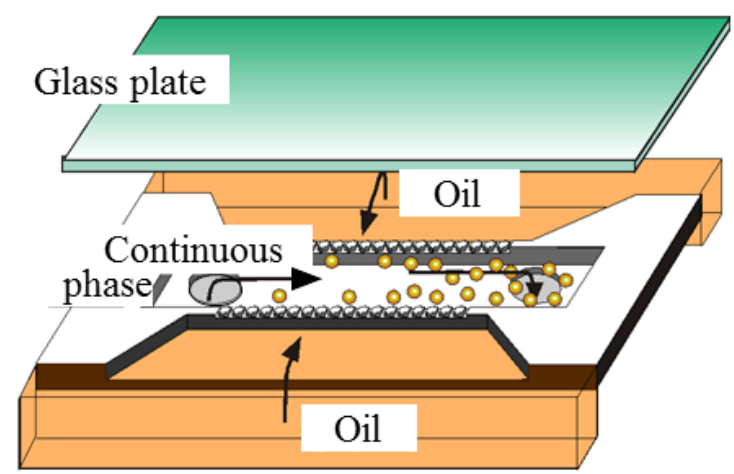

Figure 1. Grooved-type MC plates for MC emulsification.

Dead-end modules provide a dispersed phase flow rate less than $0.1 \mathrm{~mL} \mathrm{~h}^{-1}$, due to limited number of MCs (less than 2,000). Cross-flow modules with grooved MC arrays are suitable for higher production scales because multiple cross-flow channels with MC arrays can be incorporated on a single plate (Kobayashi et al 2010). A simplest cross-flow module (Fig. 1b) has only one cross-flow channel and two holes at its both ends for introduction and withdrawal of the continuous phase. The purpose of cross flow is to collect droplets from the module and not to control the droplet size. In the dripping regime, the droplet size is independent on the flow rate of dispersed or continuous phase. Cross-flow MC plates with multiple cross-flow channels are available with a maximum cross section of $60 \times 60 \mathrm{~mm}$ and 12,000 MCs arranged in 14 parallel arrays (Kobayashi et al 2010).

Modules with grooved-type plates have a limited throughput, because MCs are arranged on the plate surface in longitudinal direction and feed channels for the dispersed and continuous phase are provided on the plate surface. A vertical array of straight-through MCs fabricated by photolithography and deep reactive ion etching allows better utilisation of the plate surface resulting in significantly higher throughputs. Straight-through MCs may have a 
symmetric and asymmetric structure. Symmetric MCs (Fig. 2a) are of the same size and shape (e.g., circular or rectangular) along the whole cross section of the plate. Rectangular MCs provide better control of monodispersity than circular MCs and an aspect ratio of the slots should be at least 3 (Kobayashi et al 2004). Asymmetric MC plate has circular channels on the upstream (bottom) side and slots on the downstream (top) side (Fig. 2b). Asymmetric plate is useful when the dispersed phase viscosity is less than $1 \mathrm{mPa} \mathrm{s}$, e.g. when the dispersed phase is a volatile hydrocarbon (Kobayashi et al 2005). Straight-through micronozzle (MN) array (Fig. 2c) are used to increase the velocity of continuous phase around the growing droplets during detachment, because the channel outlets are above the plate surface, which could be useful if the viscosity of the dispersed phase is high (Sugiura et al 2005).

(a) Symmetric MC plate
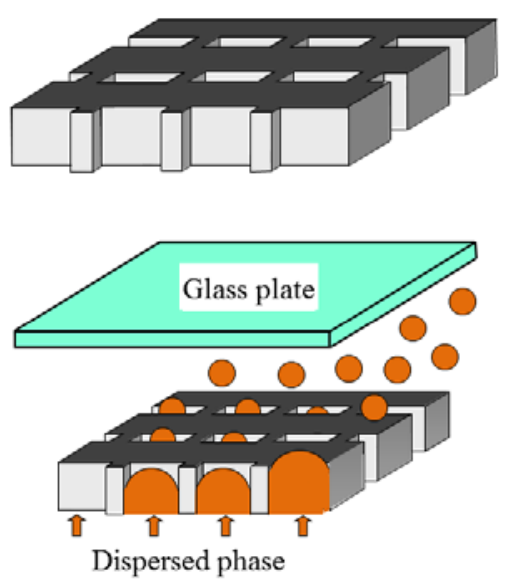

(b) Asymmetric MC plate
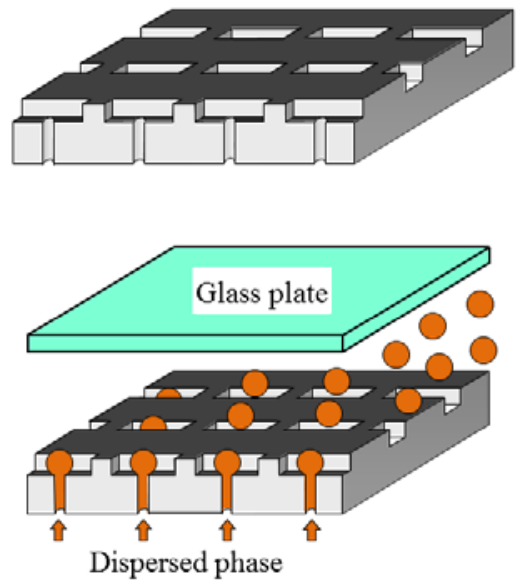

(c) Symmetric MN plate
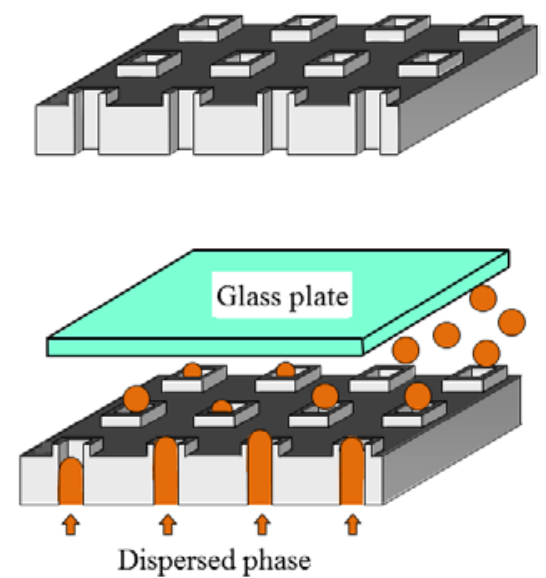

Figure 2. Straight-through MC plates for MC emulsification.

\section{References}

Kikuchi Y, Sate K, Ohki H, Kaneko T (1992) Optically accessible microchannels formed in a single-crystal silicon substrate for studies of blood rheology. Microvasc Res 44:226-240.

Kobayashi I, Nakajima M, Chun K, Kikuchi Y, Fujita H (2002) Silicon array of elongated through-holes for monodisperse emulsion droplets. AIChE J 48:1639-1644.

Kobayashi I, Mukataka S, Nakajima M (2004) Effect of slot aspect ratio on droplet formation from silicon straight-through microchannels. J Colloid Interface Sci 279:277-280. 
Kobayashi I, Mukataka S, Nakajima M (2004) Novel asymmetric through-hole array microfabricated on a silicon plate for formulating monodisperse emulsions. Langmuir 21:7629-7632.

Kobayashi I, Wada Y, Uemura K, Nakajima M. (2010) Microchannel emulsification for mass production of uniform fine droplets: integration of microchannel arrays on a chip. Microfluid Nanofluid 8:255-262.

Sugiura S, Nakajima M, Kumazawa N, Iwamoto S, Seki M (2002) Characterization of spontaneous transformation-based droplet formation during microchannel emulsification. $\mathrm{J}$ Phys Chem B 106:9405-9409.

Sugiura S, Oda T, Izumida Y, Aoyagi Y, Satake M, Ochiali A, Ohkohchi N, Nakajima M (2005) Size control of calcium alginate beads containing living cells using micro-nozzle array. Biomaterials 26:3327-3331. 